\title{
Tunning the Physical Properties of PVDF/PVC/ Zinc Ferrite Nanocomposites Films for More Efficient Adsorption of Cd (II)
}

\author{
Rania Ramadan ( $\square$ rramadan@sci.cu.edu.eg ) \\ Cairo University https://orcid.org/0000-0002-0941-3392 \\ Asmaa Ismail \\ National Research Centre
}

\section{Research Article}

Keywords: PVDF/PVC, ZnFe2O4 NPs, heavy metal removal of Cd(II)

Posted Date: September 29th, 2021

DOI: https://doi.org/10.21203/rs.3.rs-935328/v1

License: (c) (i) This work is licensed under a Creative Commons Attribution 4.0 International License.

Read Full License

Version of Record: A version of this preprint was published at Journal of Inorganic and Organometallic Polymers and Materials on January 31st, 2022. See the published version at https://doi.org/10.1007/s10904-021-02176-x. 


\title{
Tunning the physical properties of PVDF/PVC/ Zinc ferrite nanocomposites films for more efficient adsorption of Cd (II) Rania Ramadan $^{1 *}$, A. M. Ismail ${ }^{2}$
}

${ }^{1}$ Materials Science Lab (1), Physics Department, Faculty of Science, Cairo University, Giza, Egypt.

${ }^{2}$ Spectroscopy Department, National Research Centre, 33 El Bohouth Street, Dokki, 12622, Giza, Egypt.

*Corresponding author: Rania Ramadan (rramadan@sci.cu.edu.eg)

\begin{abstract}
This work studies the enhancement of the physical properties PVDF/PVC blend by adding $\mathrm{ZnFe}_{2} \mathrm{O}_{4}$ with different weight percent (from $0 \%$ up to $10 \%$ ) as a nanofiller. The effect of $\mathrm{ZnFe}_{2} \mathrm{O}_{4}$ on behavior of PVDF/PVC was studied through XRD, FTIR, FESEM and UV-Visible spectroscopy. The PVDF/PVC/ $10 \% \mathrm{ZnFe}_{2} \mathrm{O}_{4}$ nanocomposite film was represented the optimum sample. As it shows maximum crystallinity, roughness average (414 nm) and root mean square roughness $(113 \mathrm{~nm})$ on another hand this sample has also the lowest value of energy band gap for direct and indirect transition. The removal efficiency of $\mathrm{Cd}(\mathrm{II})$ by using PVDF/PVC/ $10 \%$ $\mathrm{ZnFe}_{2} \mathrm{O}_{4}$ reached to about $50 \%$ at $\mathrm{pH} 6$ after $60 \mathrm{~min}$. the absorption mechanism as well as kinetics isotherm have been studied.
\end{abstract}

Key words: PVDF/PVC; $\mathrm{ZnFe}_{2} \mathrm{O}_{4} \mathrm{NPs}$; heavy metal removal of $\mathrm{Cd}(\mathrm{II})$

\section{Introduction}

The destruction of water supplies seems to be one of the most urgent environmental issues in the world. Water resources pollution is caused by heavy metals incorporation, such as, cadmium, mercury, lead and chromium [1]. In last decades, whole world becomes very concerned with pollution of water by heavy metals. Because of its highly toxicity and nondegradability dissimilar organic pollutants as they are biodegradable [2]. One of the most harmful heavy metal ions is $\mathrm{Cd}(\mathrm{II})$, which causes kidney failure and bone brittleness. In 1968, it was considered as the first disease occurred by pollution of the environment [3]. Recently, Numerous techniques were used for treatment and reuse of contaminated water by heavy metal ions involving, ion exchange [4], reverse osmosis [5], membrane filtration [6], chemical precipitation [7] and adsorption [8]. Among all previous techniques, Adsorption is the most desirable technique due to its low cost, reproducibility, and effectiveness [9]. Adsorption of 
heavy metals are related to Adsorbent as well as adsorbate. For adsorbent, the uptake of heavy metals is affected by its concentration, $\mathrm{Ph}$, and contact time. Also, the adsorbate plays an important role in heavy metal removal. The removal of heavy metals can be done by the lattices which existed in spinel ferrite's structure [10].

$\mathrm{ZnFe}_{2} \mathrm{O}_{4}$ is attracted attention due to its magnetic behavior, chemically stability and larger surface area [11]. The chemical stability and removal efficiency of $\mathrm{ZnFe}_{2} \mathrm{O}_{4}$ can be enhanced by adding different types of polymers [12]. As, the polymer have chemical stability, good processability and flexibility [13]. Though, there are various types of polymers, poly (vinylidene fluoride) is considered one of the most desirable polymers because of it has high flexibility, electroactive nature, and easily to prepare in films form with different size and shape [14]. While PVC (poly vinyl chloride) is used because of its good mechanical, commercially available and easy processibility [15].

Herein, $\mathrm{ZnFe}_{2} \mathrm{O}_{4}$ nanosample was synthesized by flash method and combined with different concentrations to PVDF and $\mathrm{PVC}$ to form $\mathrm{PVDF} / \mathrm{PVC} / \mathrm{x} \mathrm{ZnFe}_{2} \mathrm{O}_{4}$ ( $\mathrm{x}=3,7,10$ wt.\%) nanocomposites films to be used for heavy metal $\mathrm{Cd}(\mathrm{II})$ removal from wastewater. The batch experiment was studied under various parameters such as $\mathrm{pH}$, contact time and weight ratio of adsorbate, to determine the optimum conditions for maximum removal of $\mathrm{Cd}(\mathrm{II})$.

\section{Materials and methods}

\subsection{Materials}

PVDF (Alfa Aesar 44080), High-molecular-weight PVC (Fluka), Zinc nitrate $\left[\mathrm{Zn}\left(\mathrm{NO}_{3}\right)_{2} \cdot 6 \mathrm{H}_{2} \mathrm{O}\right]$, iron nitrate $\left[\mathrm{Fe}\left(\left(\mathrm{NO}_{3}\right)_{3} \cdot 9 \mathrm{H}_{2} \mathrm{O}\right]\right.$, Tetrahydrofuran solution $(\mathrm{THF})$ and urea $\left[\mathrm{CH}_{4} \mathrm{~N}_{2} \mathrm{O}\right]$ were purchased from LOBA, india.

\subsection{Preparation of $\mathbf{Z n}$-ferrite}

Nanosample $\mathrm{ZnFe}_{2} \mathrm{O}_{4}$ was synthesized by using flash method. Proper amounts $(0.1 \mathrm{M})$ of iron and Zinc nitrates mixed well in powder phase with (0.7) urea. After that, the temperature of mixture was raised to $250^{\circ} \mathrm{C}$ till all fumes were ended. The obtained powder was calcinated at $800^{\circ} \mathrm{C}$ for $2 \mathrm{hrs}$. 


\subsection{Preparation of PVDF/PVC/ Zinc ferrite nanocomposites films}

PVDF and PVC powders were dried at $60{ }^{\circ} \mathrm{C}$ in a vacuum oven for around 2 hours to remove any moisture content. Equal quantity of PVDF and PVC was dissolved in Tetrahydrofuran solution (THF) separately until complete solubility, and then polymers added to each other and stirred continuously until homogenous solution was formed. Zinc ferrite NPs was added to blend solution with weight percentage ( $3,7,10 \mathrm{wt}$ \%). The nanocomposite solution was sonicated using dip sonicator to prevent aggolomeration of nanoparticles and the solution was transferred into Petri dish and left in drier at $40{ }^{\circ} \mathrm{C}$ around 6 hours.

\subsection{Measurement Techniques}

XRD analysis of the produced samples was proceeded via PANalyticalX'Pert Pro target $\mathrm{Cu}$ $\mathrm{K} \alpha$ with secondary monochromator Holland radiation with tube running at $45 \mathrm{kV}$ and wavelength $=0.1540 \mathrm{~nm}$. High-resolution transmission electron microscope (HRTEM) was applied by JEM-2100F electron microscope with $200 \mathrm{kV}$ accelerating voltage. ATR-FTIR spectral was used in the range 4000-400 $\mathrm{cm}^{-1}$ via spectrometer VERTEX 80 (Bruker Corporation, Germany). UV-Vis absorption spectra were performed from 200-1000 nm wavelength using Jasco UV- Vis (V-630) made in Japan. FESEM was tested using Quanta 250 FEG worked at 20-30 kV. 3D micrographs as well as roughness parameters were obtained from FESEM images for each sample by using Gwyddion soft ware.

\subsection{Batch experiment of heavy metal (Cd(II)) removal}

The experiment was carried out in $250 \mathrm{~mL}$ flasks with $(0.1 \mathrm{~g})$ of produced films in $2 \mathrm{ppm}$ of metals nitrate to determine the appropriate $\mathrm{pH}$ values for heavy metal $\left(\mathrm{Cd}^{2+}\right)$ removal. The $\mathrm{pH}$ of the solution was changed from 2 to 8 . The investigated solutions were thoroughly mixed for 1 hour at room temperature using an electric shaker (ORBITAL SHAKER SO1) at $200 \mathrm{rpm}$. After that, the solutions were collected using a $0.2 \mathrm{~m}$ syringe filter. At $25^{\circ} \mathrm{C}$, atomic absorption spectroscopy (Zeenite 700P, Analytical Jena) was used to determine the heavy metal concentration. Every experiment was repeated three times, with the average results reported.

The optimum contact time was determined by repeating the previous process while keeping the $\mathrm{pH}$ at its optimal level and measuring atomic absorption after various contact times (1 to $24 \mathrm{~h}$ ). The film removal efficiency is computed using the following formula [16]. 
Removal (adsorption) efficiency $\%=\frac{C_{0}-C_{f}}{C_{o}} \times 100 \%$

where:

$$
\begin{gathered}
\mathrm{C}_{0} \text { : heavy metal soln at initial concentration (ppm) } \\
\mathrm{C}_{\mathrm{f}} \text { : heavy metal soln at final concentration (ppm) }
\end{gathered}
$$

\section{Results and Discussion}

\subsection{Structural study}

Figure (1) shows XRD pattern of PVDF, $\mathrm{PVC}$ and $\mathrm{PVDF} / \mathrm{PVC} / \mathrm{ZnFe}_{2} \mathrm{O}_{4}$ nanocomposite films. PVDF membrane shows two diffraction patterns at $2 \theta$ equals at $18.1^{\circ}$ and $20.3^{\circ}[17,18]$. Diffraction patterns of PVC indicated their amorphous character which have broad peaks at $2 \theta$ equals $16.6^{\circ}, 18.4^{\circ}$ and $24.3^{\circ}$ [19]. For $\mathrm{ZnFe}_{2} \mathrm{O}_{4}$ curve, the diffraction peaks of the as-prepared sample can be indexed to the cubic spinel Zn ferrite, according to the standard PDF card (No.791150). It has diffraction peaks at $2 \theta$ equals $29.7,35,56.3$ and 62.1 which corresponded to (220), (311), (511) and (440) lattice plane, respectively [20].

The Debye-Scherrer equation was used to calculate the average crystallite size (S) of $\mathrm{ZnFe}_{2} \mathrm{O}_{4}$ across the (311) crystal plane [21].

$$
S=0.9 \lambda / \beta \cos \theta
$$

Where the $\mathrm{X}$-ray wavelength is $\lambda(0.154 \mathrm{~nm}), \beta$ is the full-width at half-maximum and $\theta$ is the diffraction angle. It is seen that $\mathrm{ZnFe}_{2} \mathrm{O}_{4}$ has average crystal size equal $30 \mathrm{~nm}$.

For PVDF/PVC film displays abroad and weak diffraction peak, relating to the amorphous feature of polymers. By increasing weight ratio of $\mathrm{ZnFe}_{2} \mathrm{O}_{4}$ from $3 \%$ to $10 \%$, the crystallinity gets better and diffractions peaks become clearer comparing to $0 \%$ weight ratio of $\mathrm{ZnFe}_{2} \mathrm{O}_{4}$. So, the addition of $\mathrm{ZnFe}_{2} \mathrm{O}_{4}$ NPs at different weight percentage has a significant role in crystallinity enhancement of polymers. 

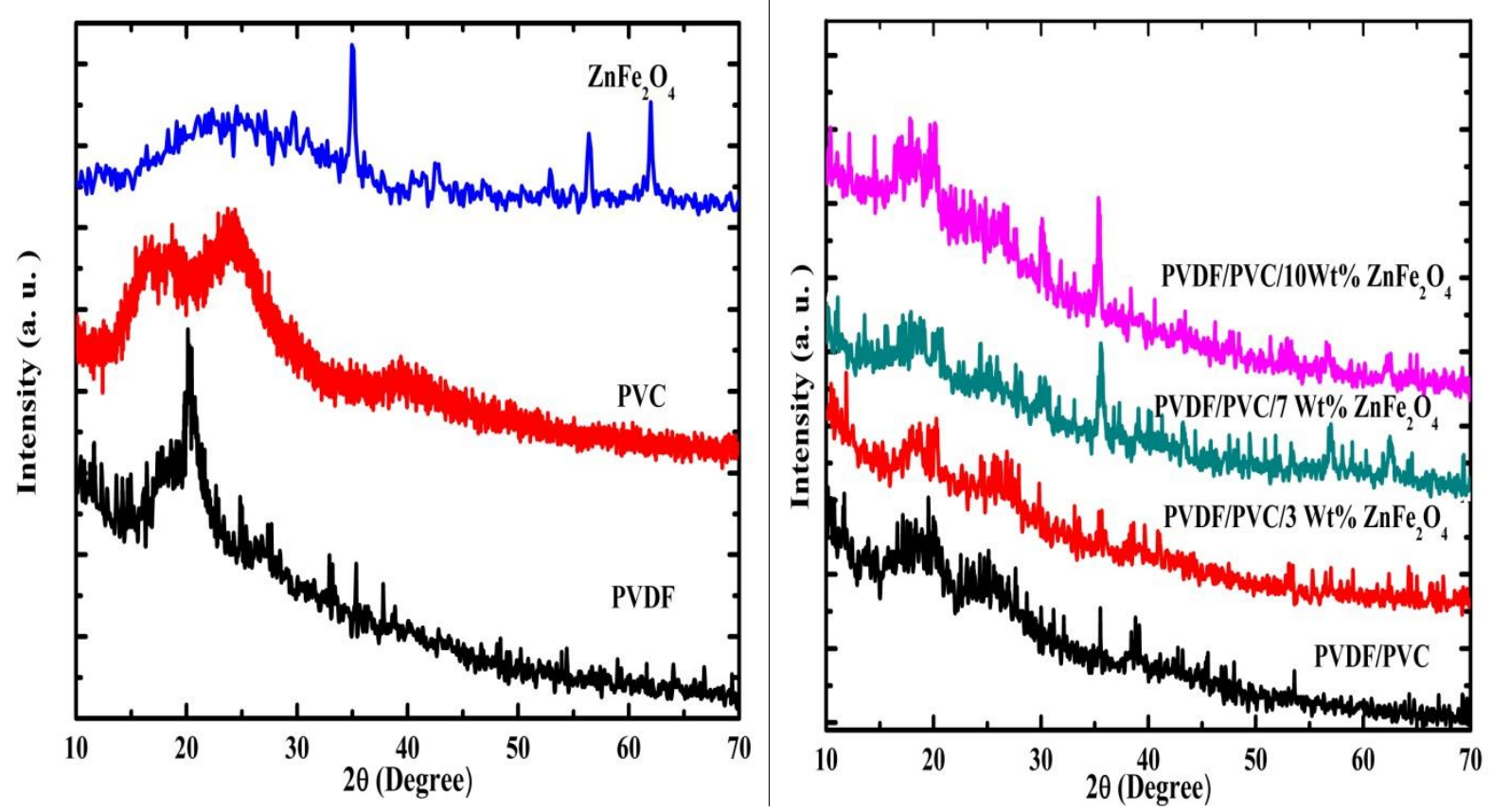

Figure (1): XRD Pattern of the prepared samples.

Figure (2) represent HRTEM of $\mathrm{ZnFe}_{2} \mathrm{O}_{4} \mathrm{NPs}$, it has irregular shapes between semi spherical and deformed cubic with average particle size ranged from 20-55 nm
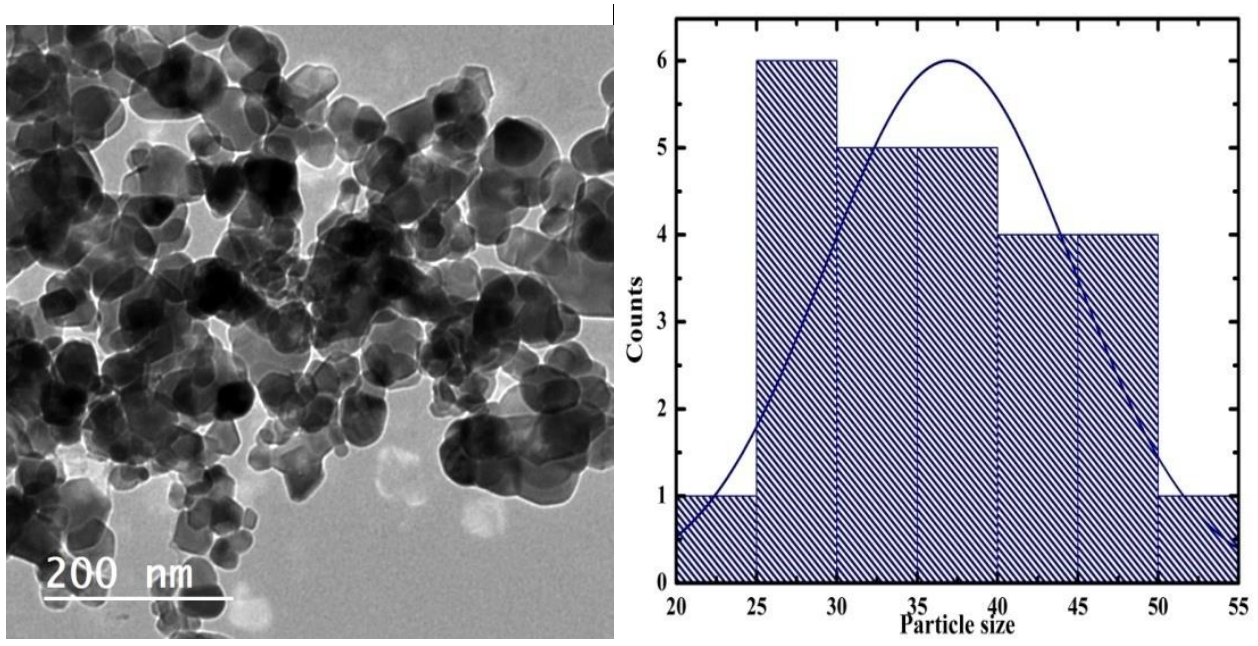


\section{Figure (2): $\mathrm{HRTEM}$ of $\mathrm{ZnFe}_{2} \mathrm{O}_{4} \mathrm{NPs}$}

Figure (3) displays FTIR spectra of PVDF, PVC and PVDF/PVC/xZnFe $\mathrm{O}_{4} ; \mathrm{x}=0 \%, 3 \%, 7 \%$ and $10 \%$ films. PVDF has characteristic band at $1400 \mathrm{~cm}^{-1}$ in the FTIR spectra of pure PVDF (Figure 2a) belongs to the $\mathrm{CH}_{2}$ wagging mode associated PVDF chain [22]. The asymmetric and symmetric stretching vibrations of $\mathrm{CF}_{2}$ were ascribed to the bands that occurred at $1179 \mathrm{~cm}^{-1}$ and $1061 \mathrm{~cm}^{-1}$, respectively. The out of plane C-H bending is shown by the band at $973 \mathrm{~cm}^{-1}$ [23]. Asymmetrical stretching vibrations of $\mathrm{C}-\mathrm{C}-\mathrm{C}$ and $\mathrm{C}-\mathrm{F}$ stretching vibrations were attributed to the bands at $870 \mathrm{~cm}^{-1}$ and $842 \mathrm{~cm}^{-1}$, respectively [24]. $\mathrm{CF}_{2}$ bending vibration was ascribed to the bands that emerged at $614 \mathrm{~cm}^{-1}$ and $489 \mathrm{~cm}^{-1}$ [25]. For PVC, the asymmetric stretching vibration of the C-H band is seen at $2913 \mathrm{~cm}^{-1}$. At $1422 \mathrm{~cm}^{-1}$, the stretching vibration of the $\mathrm{C}-\mathrm{H}$ band can be noticed. $\mathrm{CH}_{2}$ deformation and the rocking mode of the $\mathrm{C}-\mathrm{H}$ bond near $\mathrm{Cl}$ are attributed to bands at $1334 \mathrm{~cm}^{-1}$ and $1245 \mathrm{~cm}^{-1}$, respectively. At $1098 \mathrm{~cm}^{-1}$, the C-C stretching vibration is detected. Trans $-\mathrm{CH}$ and cis $-\mathrm{CH}$ wagging modes may be seen at $958 \mathrm{~cm}^{-1}$ and $614 \mathrm{~cm}^{-1}$, respectively. $\mathrm{C}-\mathrm{Cl}$ has a stretching vibration of $827 \mathrm{~cm}^{-1}$ [27-29].

For PVDF/PVC blend spectra, it combined the characteristic feature of both polymers with changing of intensity of them which affirmed that there is reaction between PVDF and PVC. For PVDF/PVC films doped with different weight ratios of $\mathrm{ZnFe}_{2} \mathrm{O}_{4}$ NPs (3\%, 7\% and 10\%). There are new bands $554 \mathrm{~cm}^{-1}$ and $421 \mathrm{~cm}^{-1}$ which are corresponded to $\mathrm{Zn}-\mathrm{O}$ bonds intrinsic stretching vibration of tetrahedral sites and $\mathrm{Fe}-\mathrm{O}$ bonds in octahedral sites, respectively [30]. Also there is new band appeared with increasing $\mathrm{ZnFe}_{2} \mathrm{O}_{4} \mathrm{NPs}$ ratio at $603 \mathrm{~cm}^{-1}$ and the intensities of bands decreased by increasing $\mathrm{ZnFe}_{2} \mathrm{O} 4$ content. The IR intensity variation can be indication on interaction between parts in prepared films. 

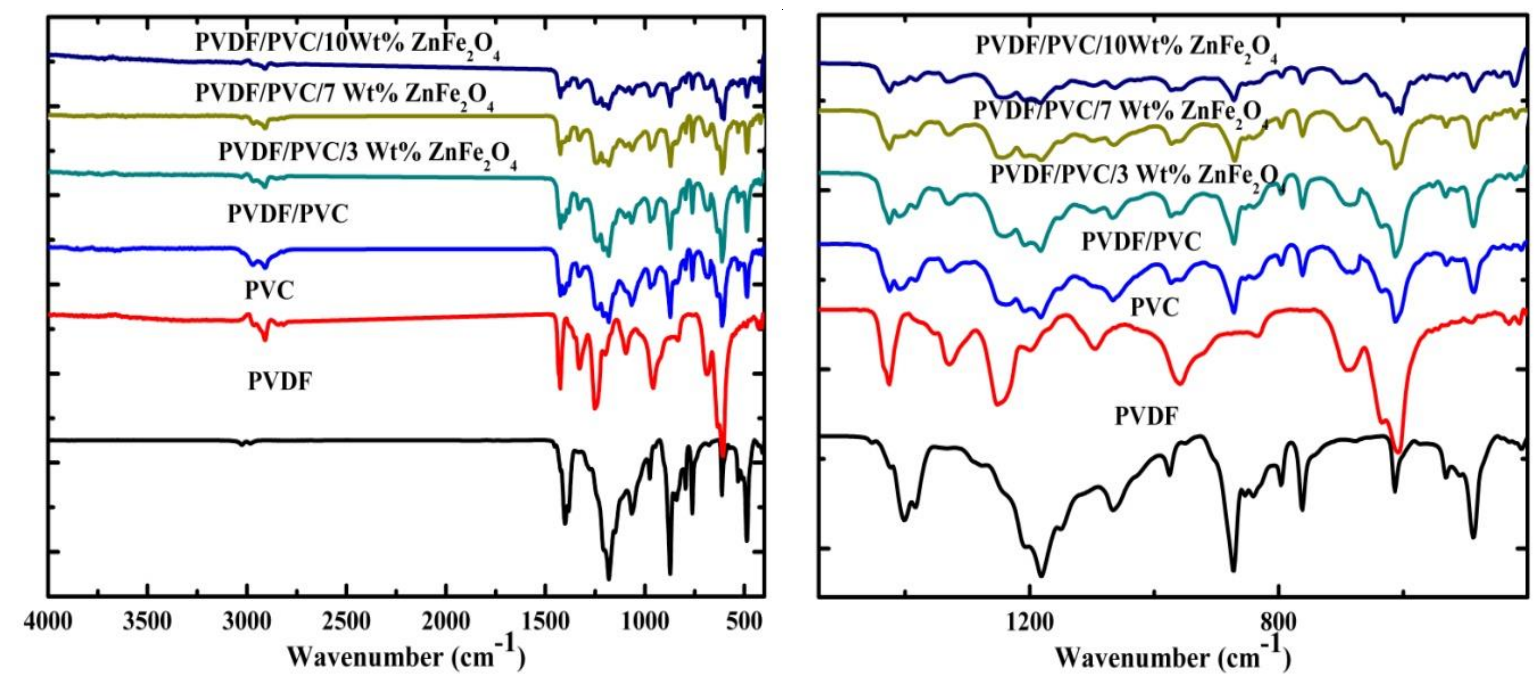

Figure (3): ATR-FTIR (transmittance mode) of the prepared samples.

Figure (4) were representative of FESEM images of prepared films. The image of surface showed that $\mathrm{ZnFe}_{2} \mathrm{O}_{4}$ nanofiller were spread homogeneously in PVDF/PVC matrices which has utilities in different applications. By increasing weigh\% content of $\mathrm{ZnFe}_{2} \mathrm{O}_{4}$ nano powder, the surfaces of the blend seem to be more roughness. Pure PVDF/PVC image shows smooth surface with high porosity.

Figure (5) displays the surface roughness of PVDF/PVC films which are doping with different weight percentage of $\mathrm{ZnFe}_{2} \mathrm{O}_{4}$ nano powder. As it obtained from Table1 all roughness parameters increased with increasing filler content. For example, roughness average has been increased from $319 \mathrm{~nm}$ to $414 \mathrm{~nm}$ while maximum height increased from $260 \mathrm{~nm}$ to $473 \mathrm{~nm}$ for $\mathrm{PVDF} / \mathrm{PVC}$ and $\mathrm{PVDF} / \mathrm{PVC} / 10 \% \mathrm{ZnFe}_{2} \mathrm{O}_{4}$, respectively. Physical adhesion for prepared films is strongly affected with these parameters (roughness average and height). As, roughness height act as hooks and facilitate the connection between films and surrounding [31]. The change in roughness parameter may be related to filler in polymeric matrices. Consequently, we can control the roughness parameters through additives in the blend according to the desired applications. 
Table 1: Roughness parameters (roughness average $\mathbf{R}_{\mathrm{a}}$, root mean square roughness $\mathbf{R}_{\mathbf{q}}$, Maximum height of roughness $\mathrm{R}_{\mathrm{T}}$ ) of $\mathrm{PVDF} / \mathrm{PVC} / \mathrm{xZnFe} \mathrm{O}_{4}$ films; $\mathrm{x}=0 \%, 3 \%$, $7 \%$ and $10 \%$

\begin{tabular}{llll}
\hline Sample & $\mathbf{R}_{\mathbf{a}}(\mathbf{n m})$ & $\mathbf{R}_{\mathbf{q}}(\mathbf{n m})$ & $\mathbf{R}_{\mathbf{T}}(\mathbf{n m})$ \\
\hline $\mathbf{X = 0}$ & 319 & 45 & 260 \\
$\mathbf{X = 3 \%}$ & 340 & 59 & 315 \\
$\mathbf{X = 7 \%}$ & 403 & 100 & 440 \\
$\mathbf{X = 1 0 \%}$ & 414 & 113 & 473 \\
\hline
\end{tabular}



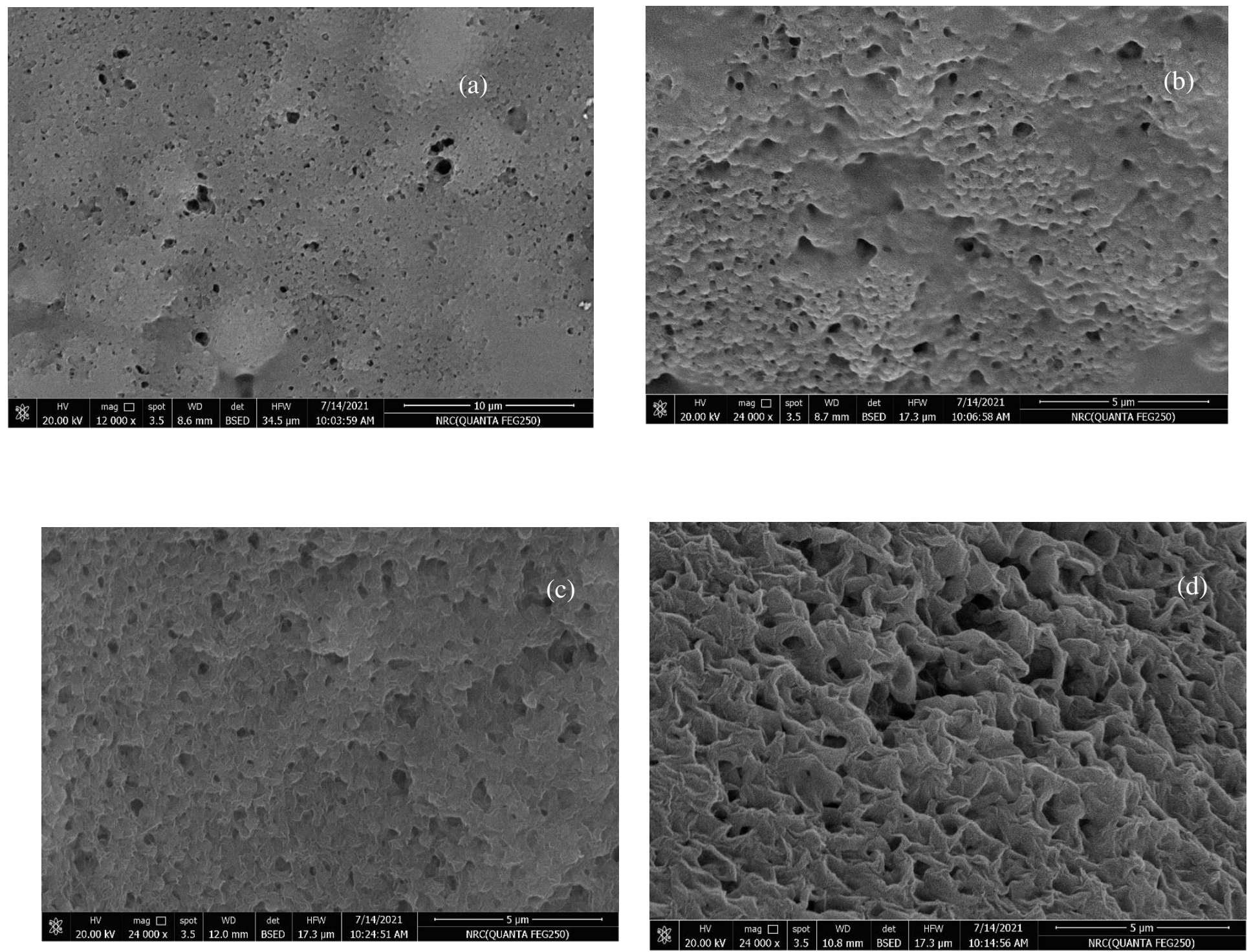

Figure (4): FESEM micrographs of PVDF/PVC/xZnFe $2 \mathrm{O}_{4}$ films; (a) $x=0 \%$, (b) 3\%, (c) $7 \%$ and (d) $\mathbf{1 0 \%}$ 


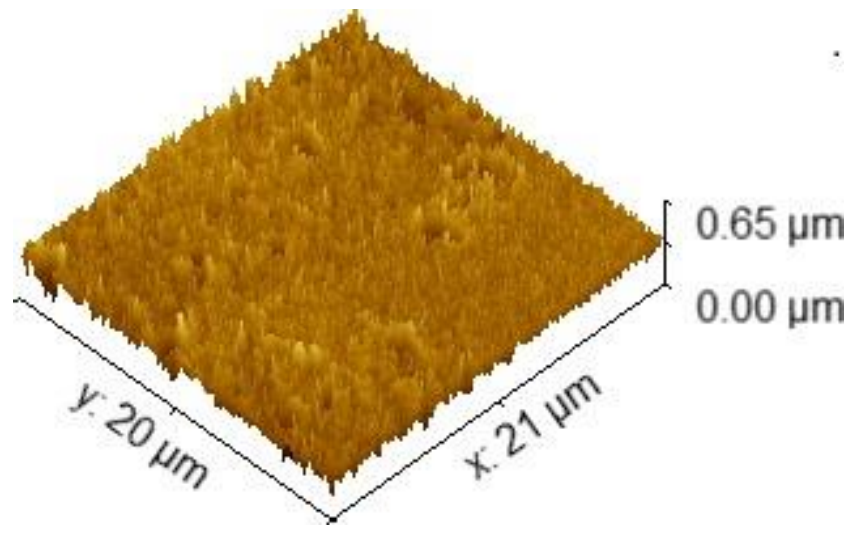

(a)

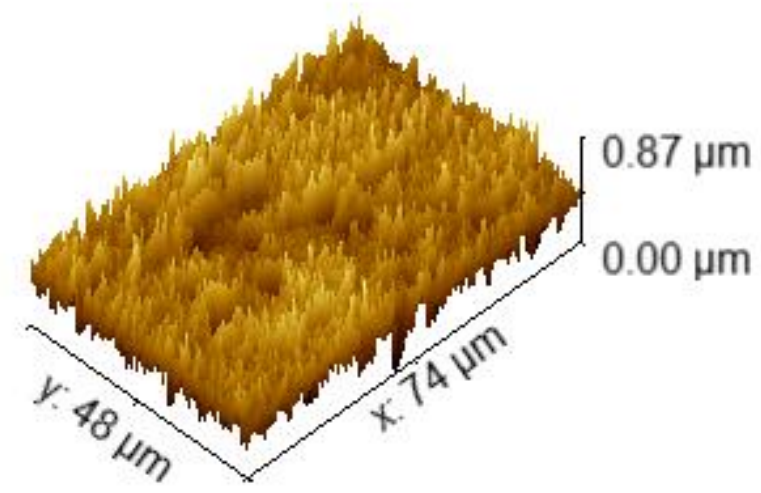

(c)

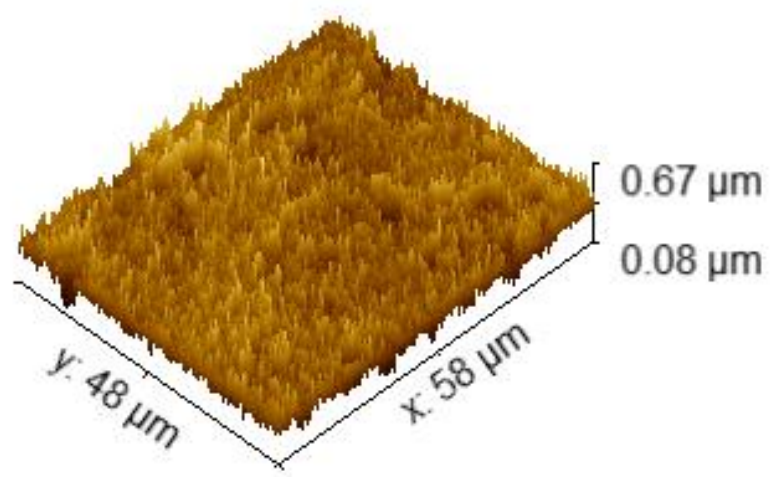

(b)

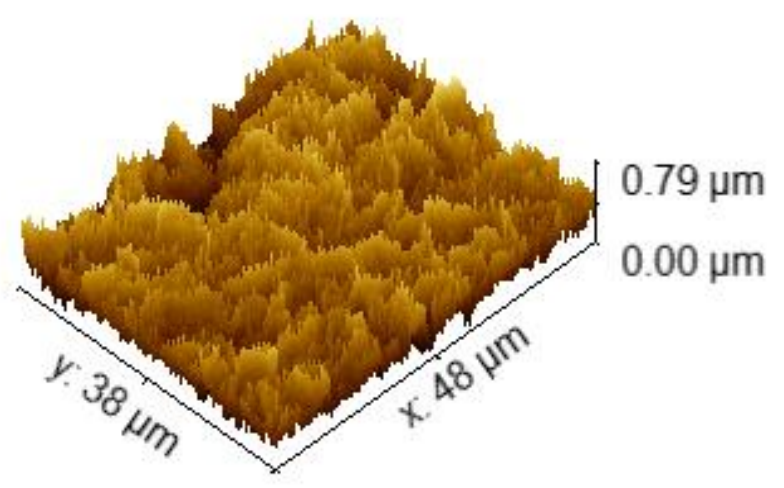

(d)

Figure (5): 3D micrographs of PVDF/PVC/xZnFe2O4films; (a) x=0\%, (b) 3\%, (c) $7 \%$ and (d) $10 \%$.

\subsection{Optical Properties}

The UV-visible spectrum is an essential measurment to calculate energy gap of amorphous and crystalline materials. The basic absorption, is related to the excitation of electron from the top of valance band to the bottom of conduction band, it also can be used for determining the value and nature of the band gap. Figure (6) which shows UV-Visible absorbance spectra of PVDF/PVC/ $\mathrm{xZnFe}_{2} \mathrm{O}_{4} ; \mathrm{x}=0 \%, 3 \%, 7 \%$ and $10 \%$ nanocomposite films. For PVDF/PVC blend, there are twp peaks at $205 \mathrm{~nm}$ and $279 \mathrm{~nm}$ which corresponded to $\mathrm{n} \rightarrow \pi^{*}$ and $\pi \rightarrow \pi^{*}$ transition which corresponded to chromophoric group of PVDF and PVC polymer blend [32,33]. As seen in for PVDF/PVC doped with different weight percentage of $\mathrm{ZnFe}_{2} \mathrm{O}_{4} \mathrm{NPs}$, the peaks at $205 \mathrm{~nm}$ shifts 
toward higher wavelength (red shift). This means that there are complexation between $\mathrm{PVDF} / \mathrm{PVC}$ and $\mathrm{ZnFe}_{2} \mathrm{O}_{4} \mathrm{NPs}$.

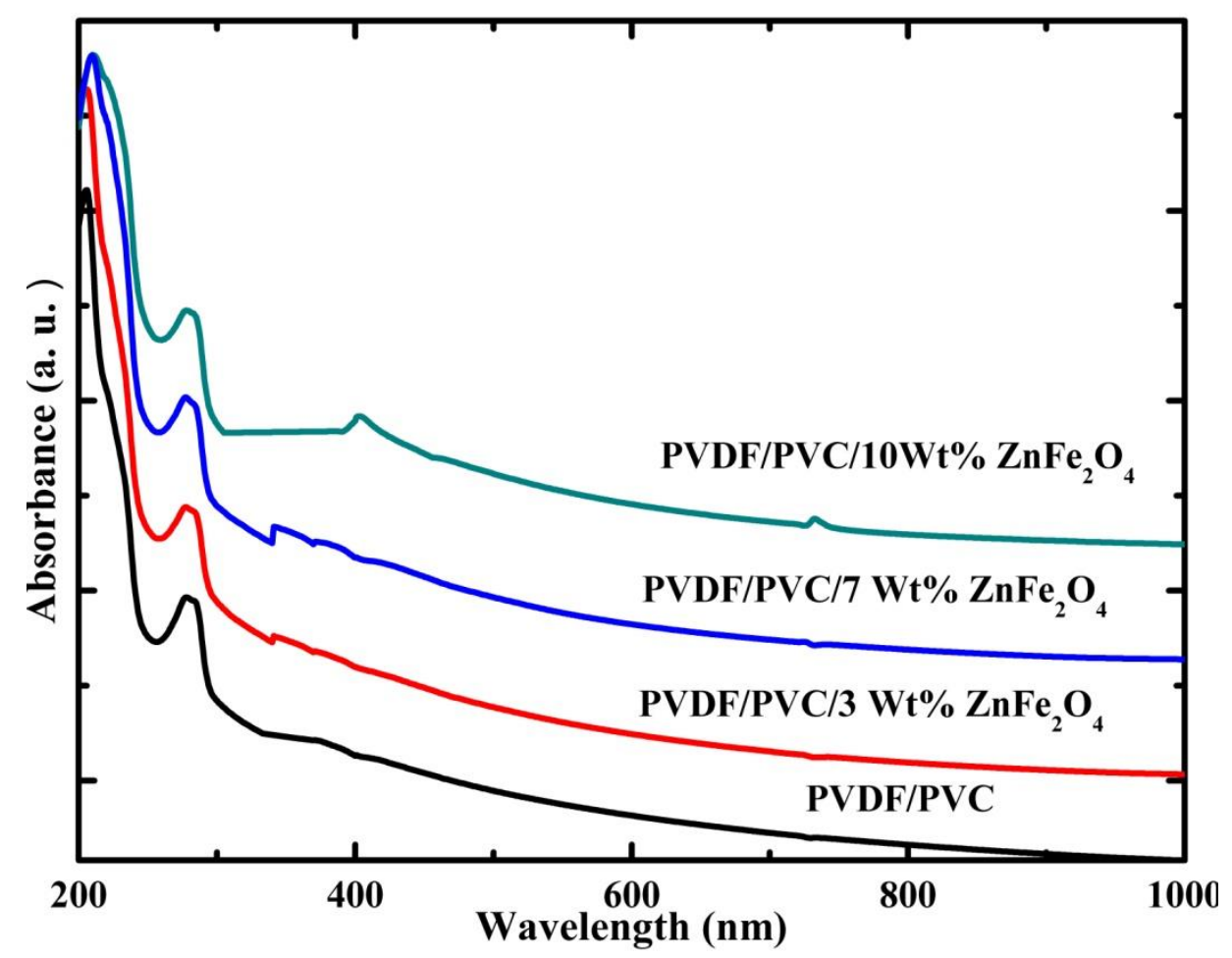

Figure (6): Uv-Vis spectra of the prepared samples.

The absorption edge defines the excitation of an electron by an incident photon from a lower energy to a higher energy state, which may be calculated by extrapolating the linear part of the absorption coefficient $(\alpha)$ with photon energy (hv). The absorption coefficient is calculated using the following equation, where $\mathrm{A}$ and $\mathrm{d}$ are the absorbance and thickness of the prepared sample [34].

$$
\alpha=\frac{2.303 A}{d}
$$

As observed in Figure (7), when compared to the PVDF/PVC blend sample, the values of the absorption edge are reduced as seen in Table 2. This is due to the formation of localized states within the band gap, as well as the changing number of final states in the system. 


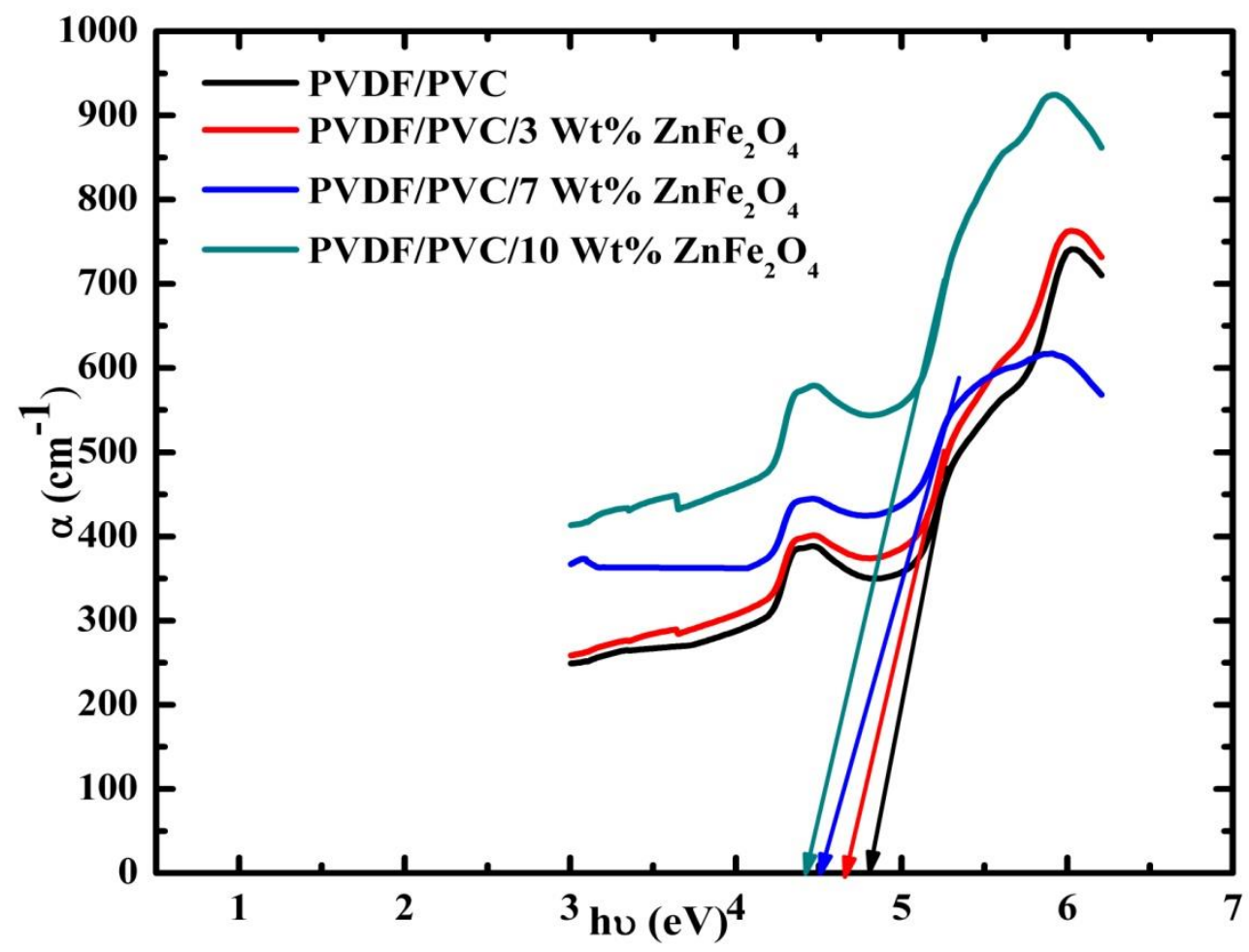

Figure (7): Absorption coefficient- photon energy relation of the prepared samples.

The optical absorption spectrum is a useful tool for calculating the optical band-gap energy of any material. The optical band gap's nature and value are checked using critical absorption, which corresponds to the electron's excitation from the valence band to the conduction band. The strong-absorption area can be studied using Tauc's equation, which is provided below [35].

$$
\begin{array}{ll}
(\alpha h v)^{2}=\alpha_{0}\left(h v-E_{g}\right) & \text { for allowed direct transition } \\
(\alpha h v)^{1 / 2}=\alpha_{0}\left(h v-E_{g}\right) & \text { for allowed indirect transition }
\end{array}
$$

Where $\alpha_{0}$ is constant. The variation of $(\alpha h v)^{2}$ and the $(\alpha h v)^{1 / 2}$ intercepting with the photon energy axis is depicted in Figure (8). Fitting the linear part of the curve and determining the intersection of the straight line with the hu axis yields the energy gap. As seen in Table 2, comparing to PVDF/PVC, the direct and indirect band gap energy values of PVDF/PVC/ $\mathrm{xZnFe}_{2} \mathrm{O}_{4}$ decrease. This result revealed that the structure of blend sample had changed, resulting in the formation of a localized state. 

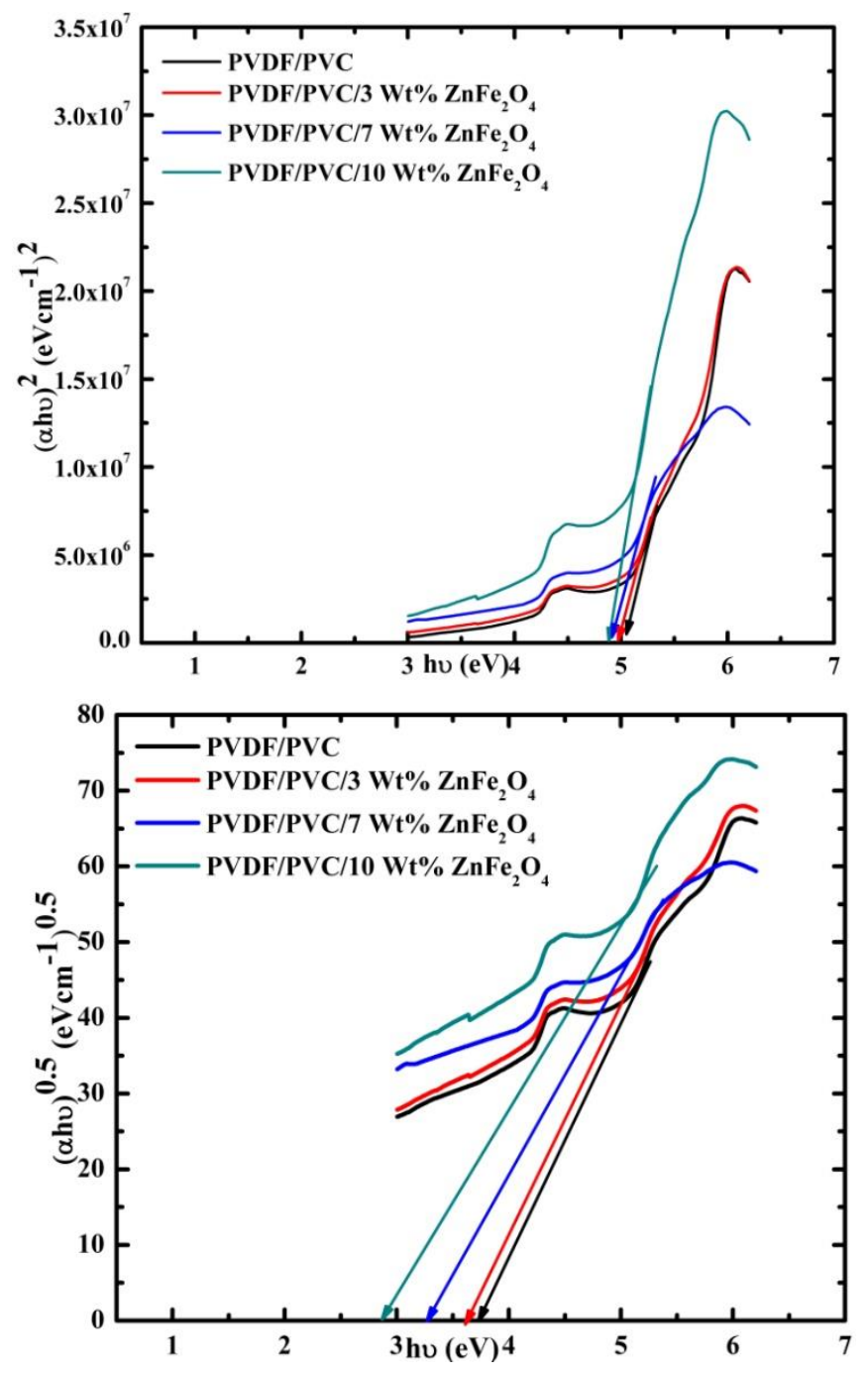

Figure (8): The variation of $(\alpha h v)^{2}$ and the $(\alpha h v)^{1 / 2}$ and hv of prepared samples.

Table 2: Absorption edge, direct and indirect transitions energy band gap values of PVDF/PVC/xZnFe $2 \mathrm{O}_{4}$ films; $x=0 \%, 3 \%, 7 \%$ and $10 \%$.

\begin{tabular}{llll}
\hline Sample & Absorption edge (eV) & Direct band gap (eV) & $\begin{array}{l}\text { Indirect band gap } \\
(\mathbf{e V})\end{array}$ \\
\hline $\mathbf{X = 0}$ & 4.8 & 5.0 & 3.7 \\
$\mathbf{X = 3 \%}$ & 4.6 & 4.9 & 3.6 \\
$\mathbf{X = 7 \%}$ & 4.5 & 4.8 & 3.3 \\
$\mathbf{X = 1 0 \%}$ & 4.4 & 4.8 & 2.9 \\
\hline
\end{tabular}




\subsection{Batch Experiment}

The $\mathrm{Cd}$ (II) up taking behavior by using PVDF/PVC/x\% $\mathrm{ZnFe}_{2} \mathrm{O}_{4}$ nanocomposite films was studied at various $\mathrm{pH}$ and contact time were used as experimental factors to find the best conditions for heavy metal removal. Figure (9) displays the $\mathrm{pH}$ solution effect on adsorption performance. It is shown that all prepared films have the same trend which is increasing $\mathrm{pH}$ is accompanied by the increasing value of the adsorption of $\mathrm{Cd}$ (II) ion. At low $\mathrm{pH}$, adsorption of $\mathrm{Cd}$ (II) has low values(from 3 to 10) \% maybe it is due to the large amount of $\mathrm{H}^{+}$which compete $\mathrm{Cd}^{2+}$ over the adsorbent's active sites [36]. By increasing value up to 6 , consequently, the number of $\mathrm{H}^{+}$decreasing and for Cd (II) adsorption, additional active sites become supplied. [37] the removal efficiency \% reached to about $30 \%$ for $\mathrm{PVDF} / \mathrm{PVC} / 10 \% \mathrm{ZnFe}_{2} \mathrm{O}_{4}$. OH- ions are present in solution at a basic $\mathrm{pH}$ (i.e. 8) causing the formation of $\mathrm{Cd}(\mathrm{OH})_{2}$ [38]. So, the up taking of $\mathrm{Cd}(\mathrm{II})$ ions were due to adsorption and precipitation. The maximum adsorption was observed for PVDF/PVC/10\% $\mathrm{ZnFe}_{2} \mathrm{O}_{4}$ as between all prepared samples this one has maximum roughness as well as maximum roughness height as mentioned above. Finally, we may infer that $\mathrm{pH} 6$ is the best choice for removal of Cd(II). 

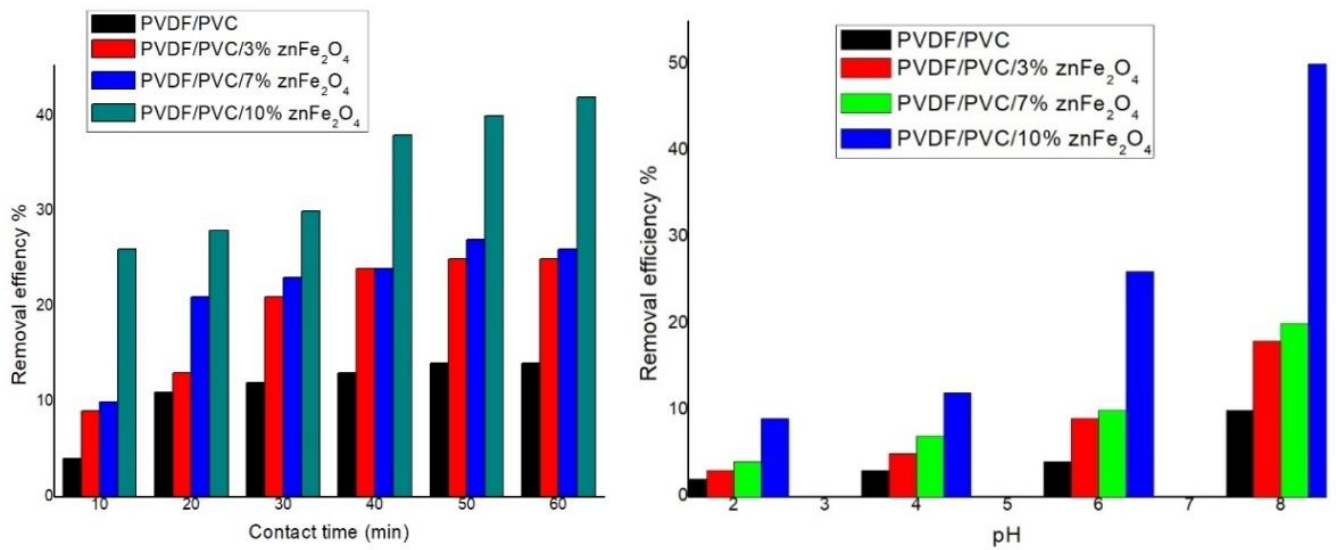

Figure (9): Removal efficiency \% of $\mathrm{Cd}$ (II) as a function of $\mathrm{pH}$ solution by using $\mathrm{PVDF} / \mathrm{PVC} / \mathrm{x} \% \mathrm{ZnFe} 2 \mathrm{O}_{4} ; \mathrm{x}=0,3,7$ and $10 \%$ nanocomposite films.

The contact time is another factor that has a significant impact on heavy metal ion adsorption. Figure (10) explains the relation between adsorption of $\mathrm{Cd}(\mathrm{II})$ ions by using $\mathrm{PVDF} / \mathrm{PVC} / \mathrm{x} \%$ $\mathrm{ZnFe}_{2} \mathrm{O}_{4} ; \mathrm{x}=0,3,7$ and $10 \%$ nanocomposite films and the contact time over range (10-60) min. It is clear, As contact time is increased, the adsorption of $\mathrm{Cd}(\mathrm{II})$ ion on surface of prepared samples also is increased. At the beginning, there were many active sites available as a result the adsorption increased by increasing contact time till the equilibrium state is reached. $\mathrm{PVDF} / \mathrm{PVC} / 10 \% \mathrm{ZnFe}_{2} \mathrm{O}_{4}$ has the highest removal efficiency, reaching nearly $50 \%$ after 60 minutes, which could be due to the amount of active sites on its surface [39]. Finally, employing a PVDF/PVC/10 \% $\mathrm{ZnFe}_{2} \mathrm{O}_{4}$ nanocomposite film, the best conditions for $\mathrm{Cd}(\mathrm{II})$ adsorption are pH 6 for 60 minutes. 


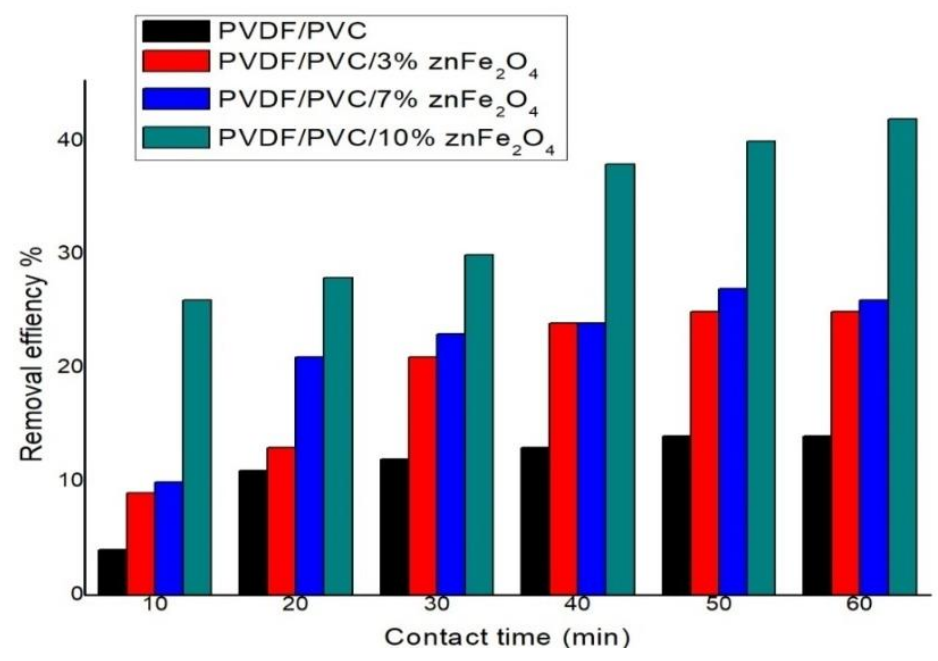

Figure (10): Relation between removal efficiency \% of $\mathrm{Cd}(\mathrm{II})$ and contact time for $\mathrm{PVDF} / \mathrm{PVC} / \mathrm{x} \% \mathrm{ZnFe} 2 \mathrm{O}_{4} ; \mathrm{x}=0,3,7$ and $10 \%$ nanocomposite films.

The only way for knowing the adsorption mechanisms which were occurred in adsorption process is done through studying adsorption isotherm and kinetics [40]. Langmuir and Freundlish isotherms are the two isotherms that are used to describe adsorption. Equations (6) and (7) were used to represent the Langmuir and Freundlish isotherms, respectively.

$\frac{C_{e}}{q_{e}}=\frac{1}{k_{l} q_{m}}+\frac{C_{e}}{q_{m}}$

$\ln q_{e}=\ln k_{f}+\frac{1}{n} \ln C_{e}$

where $q_{e}$ and $q_{m}\left(\mathrm{mg} \mathrm{g}^{-1}\right)$ denote the equilibrium and maximum adsorption capacities, respectively, and $K_{l}\left(\mathrm{~L} \mathrm{mg}^{-1}\right)$ denotes the affinity binding constant, and $K_{f}$ and n (physical constants) denote the adsorption capacity and intensity of adsorption, respectively.

The Langmuir isotherm describes monolayer adsorption at the sites which are equivalent and homogeneous with similar adsorption energies, while the Freundlish isotherm describes heterogeneous surfaces [41]. We discovered that all samples matched the Langumir model behavior by fitting Figure (11). On the other hand, fitting Figure (12) revealed that none of the samples followed the Freundlish isotherm. As a result, Cd (II) adsorption on the produced sample's surface occurred via monolayer adsorption. 

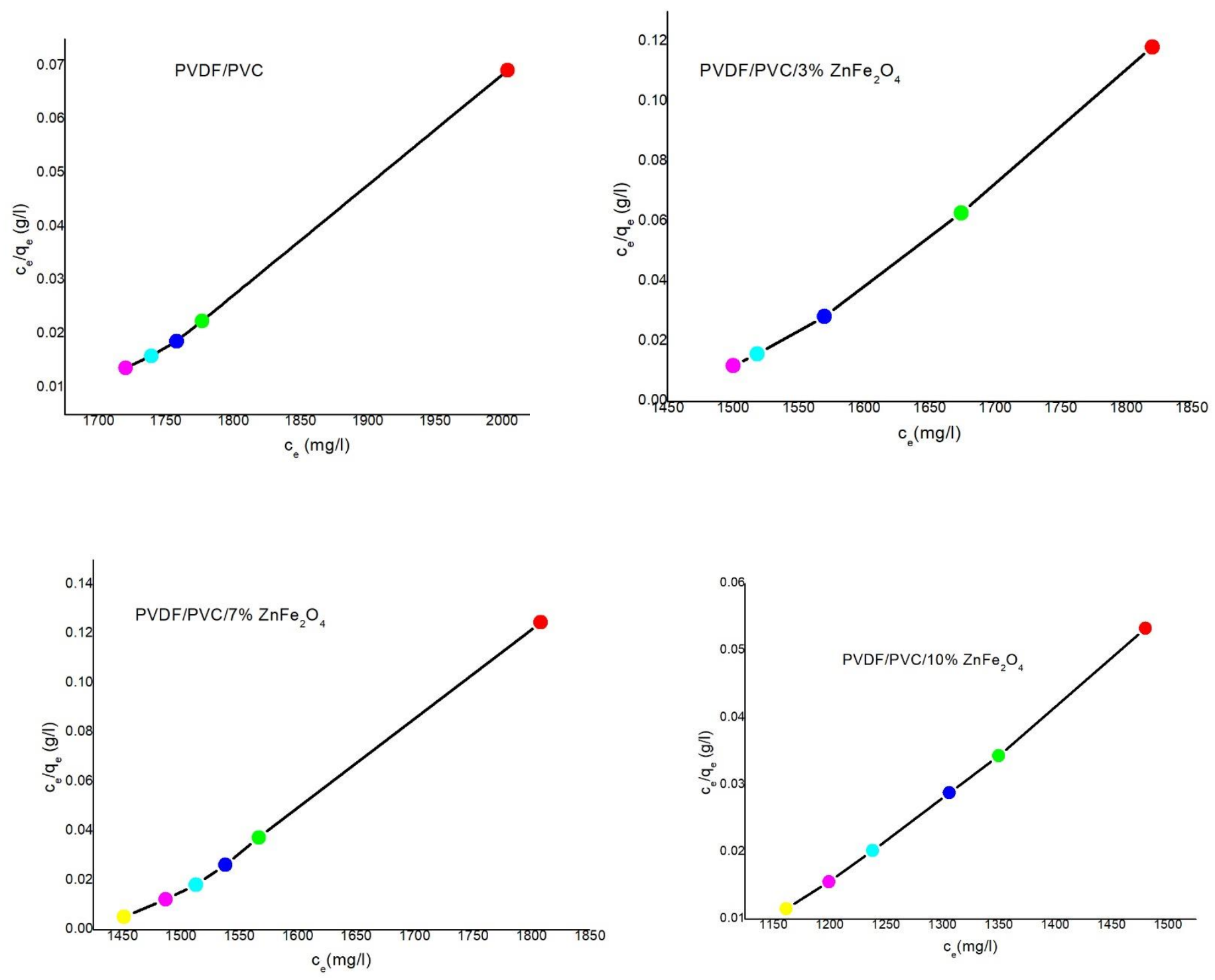

Figure (11): Langmuir isotherms for $\mathrm{PVDF} / \mathrm{PVC} / \mathrm{x} \% \mathrm{ZnFe}_{2} \mathrm{O}_{4} ; \mathrm{x}=0,3,7$ and $10 \%$. 

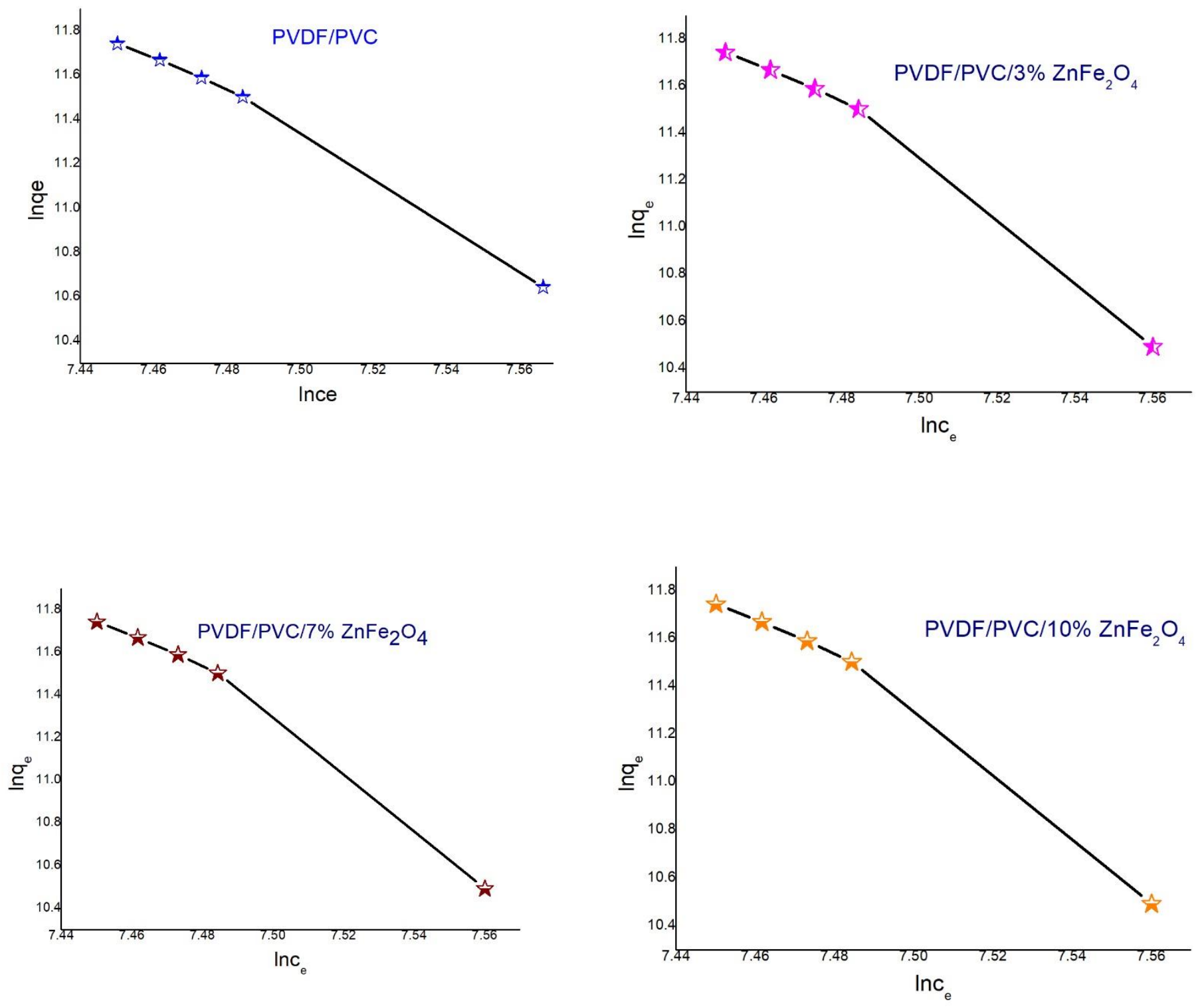

Figure (12): Freundlish isotherms for PVDF/PVC and PVDF/PVC/x\% $\mathrm{ZnFe}_{2} \mathrm{O}_{4} ; \mathrm{x}=0,3,7$ and $10 \%$.

Heavy metal adsorption kinetics were primarily explored using pseudo first order or pseudo second order kinetics. The physisorption is explained by pseudo first order kinetics. Physisorption is a weak form of adhesion that relies on vanderwaals forces rather than chemical bonds. As a result, this type of adsorption can be reversed. However, pseudo-second order kinetics is associated with chemisorption adsorption, which occurs as a result of two processes. It is the first reaction, and it soon extends equilibrium. The second, on the other hand, leaks slowly 
and takes a long time to attain equilibrium [39]. By employing electron sharing, bonds are formed between adsorbents and adsorbates in chemisorption. As a result, it is more difficult than physisorption. The intra particle diffusion kinetic model is also one of kinetic models. This model was studying by Weber and Morris model is studying. They discovered that the intra particle diffusion model is the single rate-determining stage, and adsorbate removal is carried out in a quick process [42].

Three models were used to investigate the kinetics of the adsorption mechanism:

Pseudo first-order model: $\ln \left(q_{e}-q_{t}\right)=\ln q_{e}-\frac{k_{1}}{2.303} t$

Pseudo second-order model: $\frac{\mathrm{t}}{q_{t}}=\frac{1}{k_{2} q_{e}^{2}}+\frac{\mathrm{t}}{q_{e}}$

Inter particle diffusion model $q_{t}=k_{3} t^{1 / 2}+C$

Where $\mathrm{k}_{1}, \mathrm{k}_{2}$ and $\mathrm{k}_{3}$ are the pseudo first, second order and inter particle diffusion rate constants in $\left(\mathrm{min}^{-1}\right)$ and $\left(\mathrm{g} \mathrm{mg}^{-1} \mathrm{~min}^{-1}\right)$, respectively.

Further, the majority of heavy metal ions adsorption on the surface of produced samples nanocomposites films fit well with the pseudo-second order kinetic model, refereeing to the Figure (14) compared to that for pseudo-first order Figure (13) and inter particle diffusion model Figure (15). So, the adsorption of $\mathrm{Cd}(\mathrm{II})$ by using $\mathrm{PVDF} / \mathrm{PVC} / \mathrm{x} \% \mathrm{ZnFe}_{2} \mathrm{O}_{4} ; \mathrm{x}=0,3,7$ and 10 nanocomposites films was done through Langmuir isotherm and the adsorption mechanism kinetics is pseudo second- order model. 

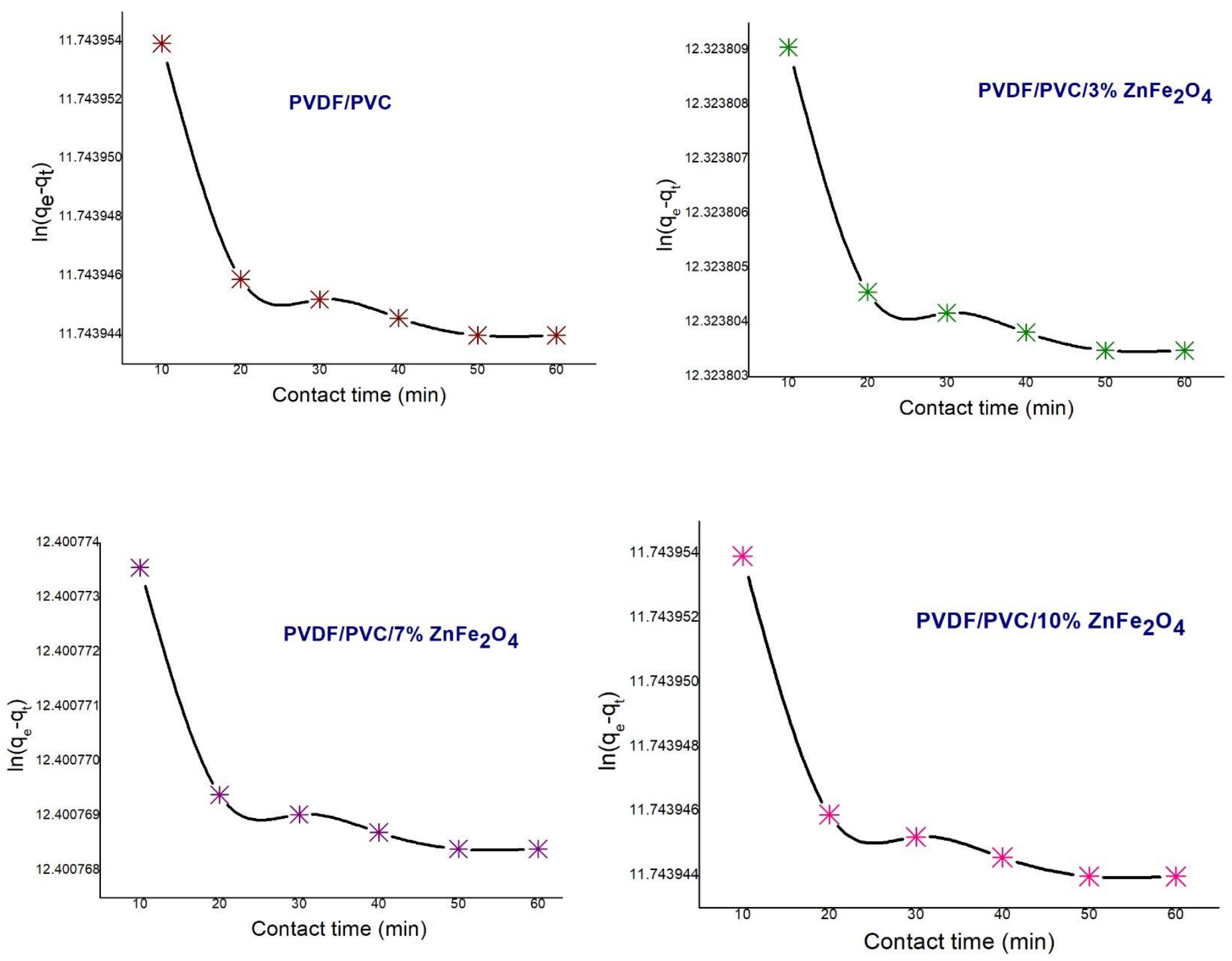

Figure (13): Pseudo-first-order model for the adsorption of Cd(II) atPVDF/PVC/ x\% $\mathrm{ZnFe}_{2} \mathrm{O}_{4} ; \mathrm{x}=0,3,7$ and 10 nano composites films. 

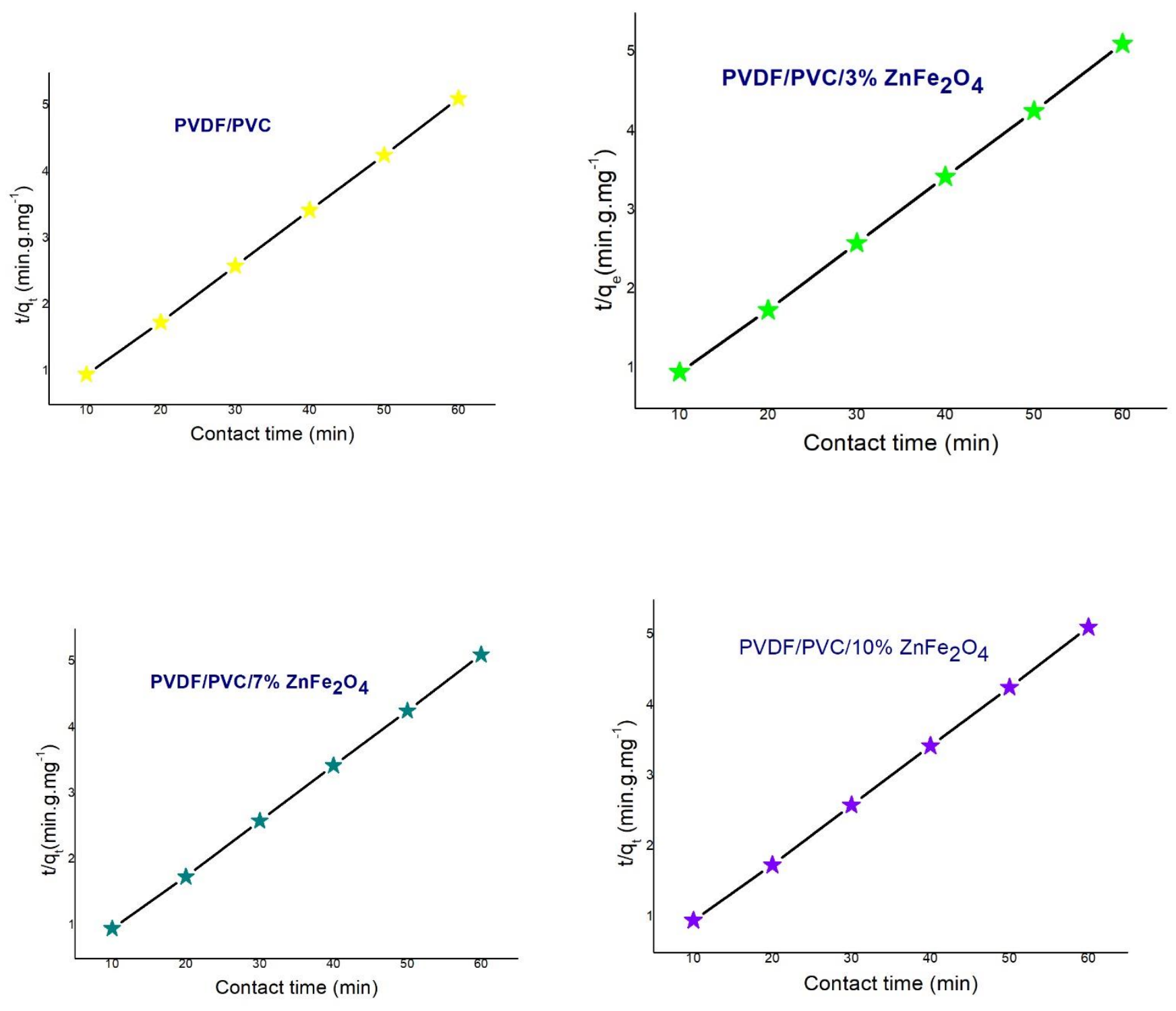

Figure (14): Pseudo-second-order model for the adsorption of Cd(II) at PVDF/PVC/ $x \%$ $\mathrm{ZnFe}_{2} \mathrm{O}_{4} ; \mathrm{x}=0,3,7$ and 10 nano composites films. 

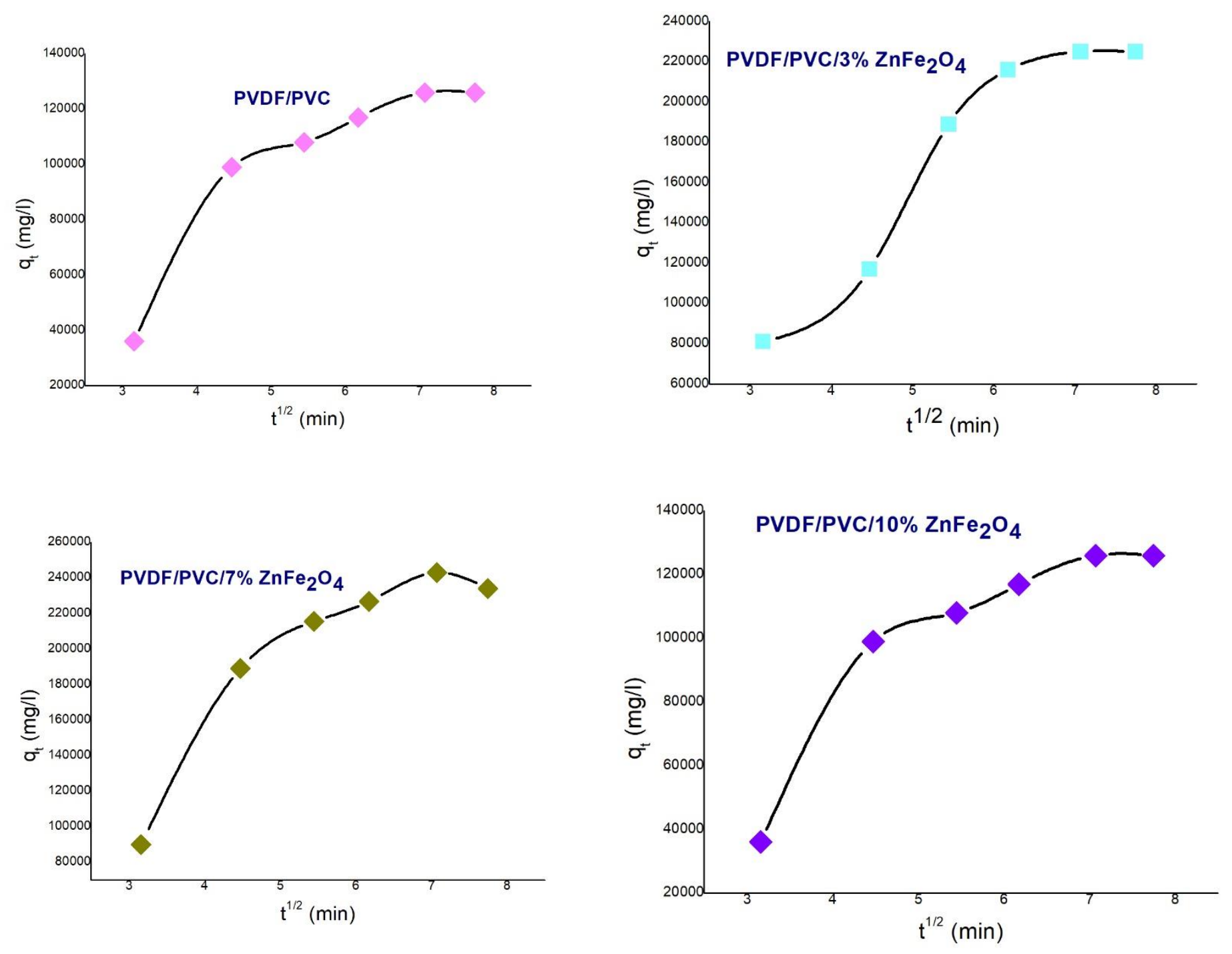

Figure (15): Intra particle model for the adsorption of $\mathrm{Cd}$ (II) at $\mathrm{PVDF} / \mathrm{PVC} / \mathrm{x} \% \mathrm{ZnFe} 2 \mathrm{O}_{4}$; $x=0,3,7$ and 10 nano composites films. 


\section{Conclusion}

$\mathrm{ZnFe}_{2} \mathrm{O}_{4}$ nano filler with different weight percentage were synthesized successfully by using flash method. These nanofillers were added to PVDF/PVC blend to form nanocomposite films of formula PVDF/PVC/x\% $\mathrm{ZnFe}_{2} \mathrm{O}_{4} ; \mathrm{x}=0,3,7$ and 10 . The structure of obtained samples was studied through XRD and FTIR, and confirmed the changing in structure and complexation between blend sample and $\mathrm{ZnFe}_{2} \mathrm{O}_{4}$ NPs. The morphology and surface of samples were observed by using FESEM, it is observed that by increasing the weight percentage the roughness and porosity have been increased. The absorption edge and band gap energy are decreased compared to blend sample. In addition to, the nanofiller enhanced the removal efficiency for Cd (II) from the wastewater which was reached to $50 \%$ at $\mathrm{pH} 6$ for $60 \mathrm{~min}$ by using $\mathrm{PVDF} / \mathrm{PVC} / 10 \%$ $\mathrm{ZnFe}_{2} \mathrm{O}_{4}$. The adsorption process was occurred through Langmuir mechanism and fellow pseudo-second order isotherm. Finally, we concluded that the sample with composition $\mathrm{PVDF} / \mathrm{PVC} / 10 \% \mathrm{ZnFe}_{2} \mathrm{O}_{4}$ has the optimum physical properties and highest removal efficiency for Cd (II).

\section{References}

[1] Zhang, Y., Peng, T., Wang, Y., Li, J., \& Zhang, Y. (2021). Modification of ZnFe2O4 by conjugated polyvinyl chloride derivative for more efficient photocatalytic reduction of $\mathrm{Cr}$ (VI). Journal of Molecular Structure, 130734.

[2] Li, F., Zhan, W., Su, Y., Siyal, S. H., Bai, G., Xiao, W., ... \& Yang, X. (2020). Achieving excellent electromagnetic wave absorption of ZnFe2O4@CNT/polyvinylidene fluoride flexible composite membranes by adjusting processing conditions. Composites Part A: Applied Science and Manufacturing, 133, 105866.

[3] Yun, S., Kirakosyan, A., Surabhi, S., Jeong, J. R., \& Choi, J. (2017). Controlled morphology of MWCNTs driven by polymer-grafted nanoparticles for enhanced microwave absorption. Journal of Materials Chemistry C, 5(33), 8436-8443.

[4] Kalanur, S. S., Yoo, I. H., Eom, K., \& Seo, H. (2018). Enhancement of photoelectrochemical water splitting response of WO3 by Means of Bi doping. Journal of catalysis, 357, 127-137. 
[5] Prasad, P. D., \& Hemalatha, J. (2019). Dielectric and energy storage density studies in electrospun fiber mats of polyvinylidene fluoride (PVDF)/zinc ferrite ( $\mathrm{ZnFe} 2 \mathrm{O} 4)$ multiferroic composite. Physica B: Condensed Matter, 573, 1-6.

[6] Martins, P., Lasheras, A., Gutiérrez, J., Barandiarán, J. M., Orue, I., \& Lanceros-Méndez, S. (2011). Optimizing piezoelectric and magnetoelectric responses on CoFe2O4/P (VDF-TrFE) nanocomposites. Journal of Physics D: Applied Physics, 44(49), 495303.

[7] Ramadan, R., El-Dek, S. I., \& Arman, M. M. (2020). Enhancement of Mn-doped magnetite by mesoporous silica for technological application. Applied Physics A, 126(11), 1-13.

[8] Zhong, Z., Cao, Q., Jing, B., Wang, X., Li, X., \& Deng, H. (2012). Electrospun PVdF-PVC nanofibrous polymer electrolytes for polymer lithium-ion batteries. Materials Science and Engineering: B, 177(1), 86-91.

[9] Gopalan, A. I., Lee, K. P., Manesh, K. M., \& Santhosh, P. (2008). Poly (vinylidene fluoride)polydiphenylamine composite electrospun membrane as high-performance polymer electrolyte for lithium batteries. Journal of Membrane Science, 318(1-2), 422-428.

[10] Ramadan, R., Ahmed, M. K., \& Uskoković, V. (2021). Magnetic, microstructural and photoactivated antibacterial features of nanostructured $\mathrm{Co}-\mathrm{Zn}$ ferrites of different chemical and phase compositions. Journal of Alloys and Compounds, 856, 157013.

[11] Lin, Y. C., Liu, K. M., Chao, C. M., Wang, D. K., Tung, K. L., \& Tseng, H. H. (2020). Enhanced anti-protein fouling of PVDF membrane via hydrophobic-hydrophobic adsorption of styrene-terminated amphiphilic linker. Chemical Engineering Research and Design, 156, $273-$ 280.

[12] Abd El-Kader, M. F. H., Awwad, N. S., Ibrahium, H. A., \& Ahmed, M. K. (2021). Graphene oxide fillers through polymeric blends of PVC/PVDF using laser ablation technique: electrical, antibacterial, and thermal stability. Journal of Materials Research and Technology.

[13] Ateia, E. E., Ramadan, R., \& Shafaay, A. S. (2020). Efficient treatment of lead-containing wastewater by $\mathrm{CoFe} 2 \mathrm{O}$ 4/graphene nanocomposites. Applied Physics A, 126(3), 1-8. 
[14] Prasad, P. D., \& Hemalatha, J. (2021). Multifunctional films of poly (vinylidene fluoride)/ZnFe2O4 nanofibers for nanogenerator applications. Journal of Alloys and Compounds, 854, 157189.

[15] Elashmawi, I. S., Alatawi, N. S., \& Elsayed, N. H. (2017). Preparation and characterization of polymer nanocomposites based on PVDF/PVC doped with graphene nanoparticles. Results in physics, 7, 636-640.

[16] Wang, J., Tong, X., \& Zhang, Y. (2011). Synthesis and characterization of graphene single sheets. Asian Journal of Chemistry, 23(5), 2281. [17] Ismail, A. M., Menazea, A. A., \& Ali, H. (2021). Selective adsorption of cationic azo dyes onto zeolite nanorod-based membranes prepared via laser ablation. Journal of Materials Science: Materials in Electronics, 1-16.

[18] Janakiraman, S., Surendran, A., Ghosh, S., Anandhan, S., \& Venimadhav, A. (2016). Electroactive poly (vinylidene fluoride) fluoride separator for sodium ion battery with high coulombic efficiency. Solid State Ionics, 292, 130-135.

[19] Matos, M., Cordeiro, R. A., Faneca, H., Coelho, J. F., Silvestre, A. J., \& Sousa, A. F. (2019). Replacing di (2-ethylhexyl) terephthalate by di (2-ethylhexyl) 2, 5-furandicarboxylate for PVC plasticization: synthesis, materials preparation and characterization. Materials, 12(14), 2336.

[20] Xu, S., Ma, Y., Xu, Y., Sun, X., Geng, B., Zheng, G., \& Dai, Z. (2014). The effects of

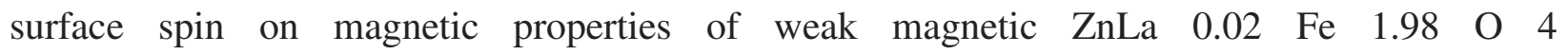
nanoparticles. Nanoscale research letters, 9(1), 1-6.

[21] Patterson, A. L. (1939). The Scherrer formula for X-ray particle size determination. Physical review, 56(10), 978.

[22] Bhran, A., Shoaib, A., Elsadeq, D., El-gendi, A., \& Abdallah, H. (2018). Preparation of PVC/PVP composite polymer membranes via phase inversion process for water treatment purposes. Chinese journal of chemical engineering, 26(4), 715-722.

[23] Tverdokhlebova, T. S., Antipina, L. S., Kudryavtseva, V. L., Stankevich, K. S., Kolesnik, I. M., Senokosova, E. A., ... \& Bolbasov, E. N. (2021). Composite ferroelectric membranes based 
on vinylidene fluoride-tetrafluoroethylene copolymer and polyvinylpyrrolidone for wound healing. Membranes, 11(1), 21.

[24] Tommalieh, M. J., Ismail, A. M., Awwad, N. S., Ibrahium, H. A., Youssef, M. A., \& Menazea, A. A. (2020). Investigation of Electrical Conductivity of Gold Nanoparticles Scattered in Polyvinylidene Fluoride/Polyvinyl Chloride via Laser Ablation for Electrical Applications. Journal of Electronic Materials, 49(12), 7603-7608.

[25] Menazea, A. A., Ismail, A. M., \& Elashmawi, I. S. (2020). The role of $\mathrm{Li}_{4} \mathrm{Ti}_{5} \mathrm{O}_{12}$ nanoparticles on enhancement the performance of PVDF/PVK blend for lithium-ion batteries. Journal of Materials Research and Technology, 9(3), 5689-5698.

[26] Ismail, A. M., El-Newehy, M. H., El-Naggar, M. E., Moydeen, A. M., \& Menazea, A. A. (2020). Enhancment the electrical conductivity of the synthesized polyvinylidene fluoride/polyvinyl chloride composite doped with palladium nanoparticles via laser ablation. Journal of Materials Research and Technology, 9(5), 11178-11188.

[27] Alghunaim, N. S. (2015). Spectroscopic analysis of PMMA/PVC blends containing CoC12. Results in Physics, 5, 331-336.

[28] Ramesh, S., Leen, K. H., Kumutha, K., \& Arof, A. K. (2007). FTIR studies of PVC/PMMA blend based polymer electrolytes. Spectrochimica Acta Part A: Molecular and Biomolecular Spectroscopy, 66(4-5), 1237-1242.

[29] Pandey, M., Joshi, G. M., Mukherjee, A., \& Thomas, P. (2016). Electrical properties and thermal degradation of poly (vinyl chloride)/polyvinylidene fluoride/ZnO polymer nanocomposites. Polymer International, 65(9), 1098-1106.

[30] Lima, E. S., Costa, L. S., Sampaio, G. R., Oliveira, E. S., Silva, E. B., Nascimento, H. O., ... \& Sasaki, J. M. (2019). Zinc ferrite nanoparticles via coprecipitation modified method: glycerol as structure directing and stabilizing agent. Journal of the Brazilian Chemical Society, 30, 882891.

[31] Raja, M. M., Lim, P. Q., Wong, Y. S., Xiong, G. M., Zhang, Y., Venkatraman, S., \& Huang, Y. (2019). Polymeric nanomaterials: Methods of preparation and characterization. In Nanocarriers for Drug Delivery (pp. 557-653). Elsevier. 
[32] Devi, P. I., \& Ramachandran, K. (2011). Dielectric studies on hybridised PVDF-ZnO nanocomposites. Journal of Experimental Nanoscience, 6(3), 281-293.

[33] Hasan, M., Kumar, R., Barakat, M. A., \& Lee, M. (2015). Synthesis of PVC/CNT nanocomposite fibers using a simple deposition technique for the application of Alizarin Red S (ARS) removal. RSC Advances, 5(19), 14393-14399.

[34] Ismail, A. M., El-Newehy, M. H., El-Naggar, M. E., Moydeen, A. M., \& Menazea, A. A. (2020). Enhancment the electrical conductivity of the synthesized polyvinylidene fluoride/polyvinyl chloride composite doped with palladium nanoparticles via laser ablation. Journal of Materials Research and Technology, 9(5), 11178-11188.

[35] Dai, L., Li, J., \& Yamada, E. (2002). Effect of glycerin on structure transition of PVA/SF blends. Journal of applied polymer science, 86(9), 2342-2347.

[36] Zhang, Y., Qi, S., Zhang, F., Yang, Y., \& Duan, G. (2011). Preparation and magnetic properties of polymer magnetic composites based on acrylate resin filled with nickel plating graphite nanosheets. Applied Surface Science, 258(2), 732-737.

[37] Bahrami, S., Yaftian, M. R., Najvak, P., Dolatyari, L., Shayani-Jam, H., \& Kolev, S. D. (2020). PVDF-HFP based polymer inclusion membranes containing Cyphos ${ }^{\circledR}$ IL 101 and Aliquat@ 336 for the removal of Cr (VI) from sulfate solutions. Separation and Purification Technology, 250, 117251.

[38] Gaikwad, M. S., \& Balomajumder, C. (2018). Removal of Cr (VI) and fluoride by membrane capacitive deionization with nanoporous and microporous Limonia acidissima (wood apple) shell activated carbon electrode. Separation and Purification Technology, 195, 305-313.

[39] Valentín-Reyes, J., García-Reyes, R. B., García-González, A., Soto-Regalado, E., \& CerinoCórdova, F. (2019). Adsorption mechanisms of hexavalent chromium from aqueous solutions on modified activated carbons. Journal of environmental management, 236, 815-822.

[40] Rajendran, S., Sivakumar, P., \& Babu, R. S. (2007). Studies on the salt concentration of a PVdF-PVC based polymer blend electrolyte. Journal of power sources, 164(2), 815-821. 
[41] Gray, F. M. (1991). Transport properties: effects of dynamic disorder. Solid Polymer Electrolytes: Fundamentals and Technological Applications, 252.

[42] J.R. MacCallum, C.A. Vincent (Eds.), Polymer Electrolytes Reviews,Elsevier Applied Science, London,2 (1989). J.R. MacCallum, C.A. Vincent (Eds.), Polymer Electrolytes Reviews,Elsevier Applied Science, London,2 (1989). 